\title{
EDITORIAL
}

\section{Popularize or publish? Growth in Australia}

\author{
Greg M. Peters
}

Received: 6 June 2009 / Accepted: 14 June 2009 /Published online: 7 July 2009

(C) Springer-Verlag 2009

\begin{abstract}
While the community of life cycle assessment (LCA) practitioners in Australia has developed relatively recently and is naturally smaller than in Europe or the United States, it is a vibrant community. The idea for this article was to examine the contribution made to LCA development by Australians, the rate of growth of this work, and its industry sectoral focus by quantitative analysis of publication data from four key LCA journals. Although these data suggest that the country's publication rate has not changed much in the last 8 years and fallen relative to the international rate, applied LCA is playing an increasing role in the work of Australian industry and government. Current efforts of the Australian LCA Society are focused on the renewal and expansion of available inventory resources, standardization of life cycle inventory methodology, and improvement of impact assessment processes.
\end{abstract}

Keywords ALCAS - Australian Life Cycle Assessment Society - Industrial relevance - Institutional development . Methodology $\cdot$ LCI $\cdot$ Life cycle inventory

\section{Qualitative observations}

In mid-1993, the author spent a week on the telephone trying to identify the life cycle assessment (LCA) work underway in Australia. This qualitative assessment suggested that it was centered on a handful of academics in Melbourne, Sydney, and Brisbane, most of whom had a

G. M. Peters $(\square)$

School of Civil and Environmental Engineering,

UNSW, Sydney, NSW 2052, Australia

e-mail: g.peters@unsw.edu.au basic understanding of LCA on the basis of overseas developments but who were looking for postgraduates to actually do one for them and drive new research. A couple of consulting organizations including Dames and Moore (today URS Corporation) had performed LCA but the results were confidential. There appeared to be only one publicly available LCA - an assessment of washing machines by Deni Greene commissioned by the Australian Consumers Association (Greene 1992).

Government initiatives in the mid-1990s such as the national EcoReDesign Demonstration Project and the need to prove that the Sydney Olympic Games would live up to its "green" marketing focused the minds of the manufacturers of packaging, household equipment, and building products and resulted in a number of LCAs. Sydney Water experimented with LCA as part of the wide-ranging "Clean Waterways Program" and BHP developed a capacity for LCA within its engineering division. There was enough interest in 1996 for the Institution of Engineers to attract 50 attendees to its first public seminar on LCA in Sydney and for the first national conference on LCA to be held in Melbourne. In the same year, the Cooperative Research Centre for Waste Management and Pollution Control (CRCWMPC), based at UNSW and including participants from the University of Queensland, CSIRO, Orica, and BHP, began organizing regular national roundtables for people interested in LCA (Grant et al. 2001; Smith 2002).

The first conference had drawn attention to the lack of life cycle inventory (LCI) data, and in 1997, the CRCWMPC, the Federal Government, and four State Governments (Victoria, New South Wales, Queensland, and South Australia) funded Australia's first LCI project. LCI for basic building and packaging materials, transport, and energy were subsequently published (Grant et al. 2001). 
A second national conference, which was held in 2000, focused on characterization methods. A survey of Australian LCA projects that year showed 26 people were doing LCA with an emphasis on buildings, building products, water, and packaging (Hes 2001). A majority (15) of this group were based at universities. The level of interest continued to grow and roundtable participants decided to create Australian Life Cycle Assessment Society (ALCAS) in 2001. Since then, national conferences have been held every 2 years on average. For many years now, Australians have participated in Society of Environmental Toxicology and Chemistry (SETAC) fora for the development of LCA, which has been a useful exercise for the participants and no doubt assisted methodological developments internationally.

\section{Quantitative analysis}

\subsection{Method}

One measure of the contribution made by Australians to the development of LCA is the number of publications in the field which include an Australian component. To examine this, one can download databases of scholarly publications from services such as Scopus and identify how many include an Australian author. Many publications report on LCAs and it would be infeasible to analyze all of the many journals of various branches of industry to identify all LCA publications. Instead, the data shown here is based on analysis of four leading journals which have been publishing articles on many different topics in LCA for more than a decade - these are listed in Table 1.

Quantitative data was obtained by searching for publications which included "life cycle assessment," "life cycle analysis," or "carbon footprint" in the title, abstract, or keywords for the last 15 years (1993-2008) as available, although the International Journal of Life Cycle Assessment and the Journal of Industrial Ecology only started publishing more recently (1996 and 1997, respectively).

The records obtained were also semiquantitatively analyzed to identify the areas of interest among the different publications. To identify and classify the relevance of the papers to different industries in the LCA studies underlying the articles, papers were initially divided into the Classifi- cation of Individual Consumption by Purpose contained in the United Nations' System of National Accounts (UN 1993). These 12 high-level divisions were expanded to increase the level of disaggregation around material products as shown in Table 2. The selection of a set of classifications is arbitrary and it is of course impossible to be absolute when classifying papers, given that the publications may refer to several industries or exist on the border between methodological development and industrial applications. For this article, where some connection with industry was possible, a publication was given the benefit of the association during classification.

\subsection{Results and discussion}

The rate of publication of LCAs in these journals is shown in Fig. 1. Since the foundation of the International Journal of Life Cycle Assessment in 1996, the publication rate has increased approximately exponentially $\left(R^{2}=0.89\right)$, growing at an average of $17 \%$ per year. Naturally, this journal has provided the principal platform supporting the development of the LCA community, publishing the majority $(57 \%)$ of the articles in this survey. A total of 1,066 publications are included in the dataset from 1993 to 2008 (inclusive). Of these, 43 (4\%) include an Australian author. While Australians might be proud of producing more than our proportion of the global population $(0.3 \%)$ or, more relevantly, the global economy (1.2\%) would suggest, it must be borne in mind that, in many cases, the papers include multiple international collaborators. As shown in Fig. 2, aside from some discrepancies in 2002 and 2006, the rate of publication by Australians in these journals stabilized by the time ALCAS was formed at an average of five publications per year. This leads to the relative outcome shown in Fig. 3, which suggests that the rate of LCA publication by Australians is not keeping pace with international growth.

There may be several reasons for this. From dialog with other analysts, the author is aware of two particular factors which have influenced publication rates: a lack of government support and a strong focus on applications. From 1995 to 2005, the Federal Government's funding for higher education did not keep pace with demand, falling from $65 \%$ to $48 \%$ of total funding, compared with a 2005 European

Table 1 Key journals for general LCA articles

\begin{tabular}{lccc}
\hline Key journal & First edition & Impact factor in 2007 & LCA articles 1993-2008 \\
\hline International Journal of Life Cycle Assessment (IJLCA) & 1996 & 1.607 & 608 \\
Journal of Cleaner Production (JCP) & 1993 & 1.073 & 187 \\
Journal of Industrial Ecology (JIE) & 1997 & 1.962 & 159 \\
Environmental Science and Technology (ES\&T) & 1967 & 4.363 & 112 \\
\hline
\end{tabular}


Table 2 Analysis of LCA applications by journal

\begin{tabular}{|c|c|c|c|c|c|c|}
\hline \multirow[b]{2}{*}{ Classification } & \multicolumn{4}{|l|}{ Journal } & \multirow[t]{2}{*}{ All } & \multirow[t]{2}{*}{ With Australian author (\%) } \\
\hline & IJLCA & $\mathrm{JCP}$ & JIE & ES\&T & & \\
\hline Food & 48 & 19 & 9 & 4 & 80 & 3.8 \\
\hline Alcoholic beverages/tobacco & 2 & 1 & & & 3 & 0 \\
\hline Clothing/footwear & 9 & 3 & & 1 & 13 & 0 \\
\hline Biofuel & 11 & 8 & 8 & 7 & 34 & 2.9 \\
\hline Electricity & 23 & 6 & 2 & 7 & 38 & 5.3 \\
\hline Fuel & 8 & 5 & 1 & 8 & 22 & 4.5 \\
\hline Housing & 29 & 3 & 4 & 6 & 42 & 0 \\
\hline Water & 11 & 6 & 3 & 5 & 25 & 12 \\
\hline Furnishing/household equipment & 15 & 1 & 2 & & 18 & 0 \\
\hline Health & 6 & 1 & 2 & & 9 & 0 \\
\hline Transport & 40 & 12 & 12 & 11 & 75 & 0 \\
\hline Communications & 6 & 4 & 6 & 6 & 22 & 0 \\
\hline Recreation/culture & & & 2 & & 2 & 0 \\
\hline Education services & 2 & 1 & 1 & 1 & 5 & 40 \\
\hline Finance & 1 & & 2 & & 3 & 0 \\
\hline Concrete & 3 & & 1 & & 4 & 25 \\
\hline Chemicals & 31 & 6 & 4 & 9 & 50 & 0 \\
\hline Metal & 21 & 6 & 2 & 6 & 35 & 5.7 \\
\hline Nanomaterials & & 4 & 11 & 3 & 18 & 0 \\
\hline Packaging & 9 & 6 & 2 & & 17 & 29 \\
\hline Paper & 3 & 5 & 4 & & 12 & 0 \\
\hline Plastics & 1 & 2 & 3 & 2 & 8 & 0 \\
\hline Waste management & 46 & 18 & 12 & 7 & 83 & 2.4 \\
\hline Wood & 13 & 3 & 2 & 1 & 19 & 0 \\
\hline Miscellaneous goods and services & 1 & 3 & 2 & & 6 & 17 \\
\hline Method and other developments & 269 & 64 & 62 & 28 & 423 & 4.5 \\
\hline Totals & 608 & 187 & 159 & 112 & 1,066 & 3.9 \\
\hline
\end{tabular}

average of $83 \%$ (OECD 2008). For the LCA industry, this would be expected to constrain basic research at universities and create a situation where consulting and government organizations attempting to hire LCA practitioners are

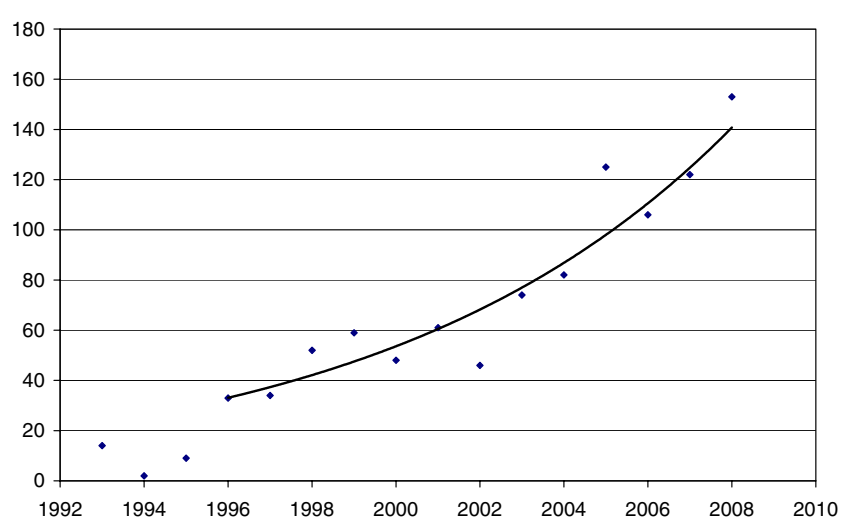

Fig. 1 Rate of publication - four journals, all nationalities (trend line excludes 1992-1995) forced to look overseas. In 2007-2008, three leading Australian LCA organizations hired key staff trained in the UK, Sweden, USA, and Germany. The consequence of the underlying situation is that LCA output may have been

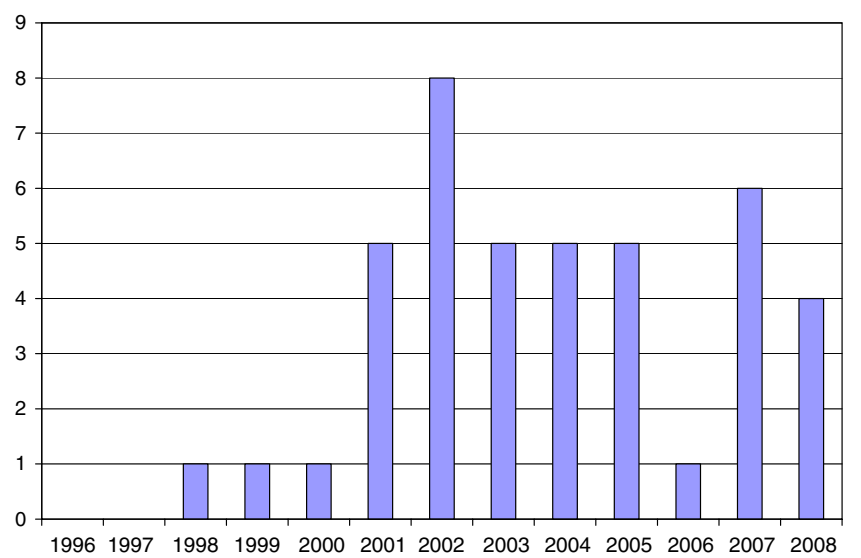

Fig. 2 Rate of publication-four journals, Australians 


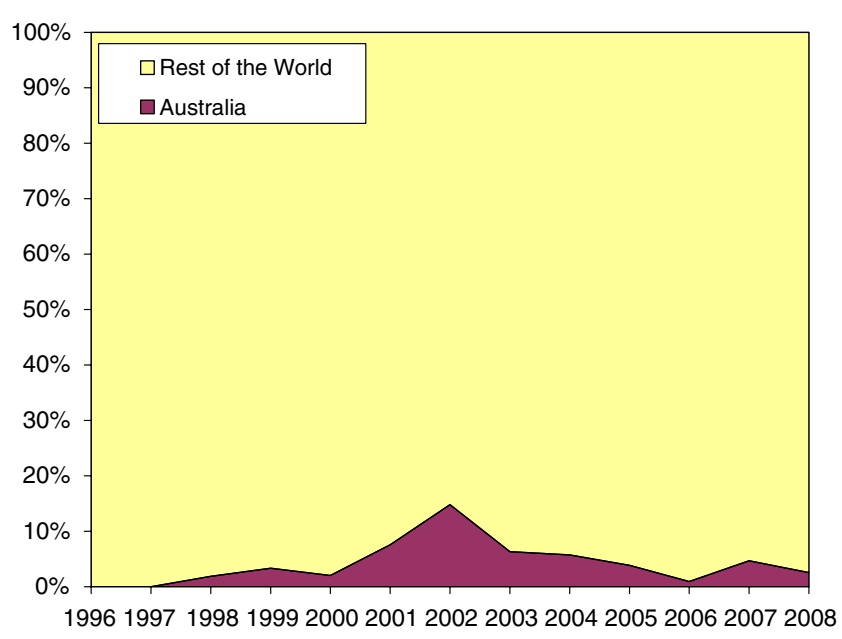

Fig. 3 LCA publications including Australian authors as a proportion of annual total

constrained by available resources in recent years. Understandably, some of the key industrial sponsors of LCA have wanted to keep the outcomes of their LCA research for their own financial and strategic benefit and forbidden publication of their LCA research at universities and elsewhere. The presence of a strong focus on industrial applications of LCA has lead to a number of useful simplified tools being developed to assist government and industry with decision-making, for example, tools focused on air-conditioning (UNSW 2008), packaging (Verghese 2008), and water services (Schulz et al. 2009). While this kind of practical LCA work is invaluable for its potential to popularize and accelerate the process, leading to more sustainable economies, it may not be as strongly associated with the kind of scientific and conceptual breakthroughs that leading journals and their peer reviewers prefer. It may also lead to a preference to publish in industry-specific journals. Nevertheless, the preliminary data for 2009 suggest that the Australian publication rate in the leading LCA journals examined in this survey will exceed its longterm average in this year.

Considering the semiquantitative analysis of LCA applications by journal shown in Table 2, it appears that Australians have had more to say about the packaging and water industries than about many others. The focus on packaging has been historically driven by government pressure on the packaging industry and its own initiatives to improve sustainability. Energy recovery from packaging waste is unusual in Australia, so there has been a strong drive in some circles to find other ways to make packaging more sustainable and minimize the quantity of packaging waste going to landfill (Verghese 2008). The application of LCA to the water and wastewater industry has been relatively successful due to the early leadership of several Australian utilities in the application of LCA for examining alternatives for water supply, disinfection, reticulation, and the treatment of wastewater and biosolids (Lundie et al. 2005).

The main surprises in these data are perhaps the weak showing in housing and transport sectors, both of which are significant industries and fields of innovation in Australia. It may be that LCA analysts working in these areas have chosen to publish in sector-specific journals read by the decision-makers in those fields. Table 2 suggests a strong Australian contribution to the assessment of educational services and concrete, however, these are as a proportion of a small total number of papers, and therefore, less numerically significant. The largest classification shown in Table 2 is publications about methodological or other aspects of LCA not clearly related to a particular industry. Researchers at the universities of Melbourne, New South Wales, and Sydney and the Royal Melbourne Institute of Technology and elsewhere in Australia have responded to various methodological challenges, including some created by the difficulty of applying a method of European origin in a continent with different natural, social, and industrial characteristics, and published a number of articles on LCA methodology. Nevertheless, the intent of this analysis was to identify which industries have been the focus of Australian LCA rather than which aspects of methodology, so there has been no attempt to subdivide this group. However, considered as a relative proportion of total output, the present data suggest that Australians have been concerned with methodological developments as much as our colleagues in the rest of the world.

\section{Recent developments}

At the most recent ALCAS conference (the sixth), there were approximately 140 delegates including 10\% from other countries. While some local presenters may have instead chosen to go to the SETAC 5th World Congress, which was held in Sydney just 6 months prior, this was around the same number as the previous ALCAS conference and the group maintained the sense that the Australian LCA industry is no longer the realm of academics that it seemed to be at the first three national conferences. Twentythree percent of delegates came from universities, slightly more from consulting firms (24\%) with good representation from government $(19 \%)$ and industry and industry peak bodies $(20 \%)$. Conferences always lead to a surge in membership, but this time, it seems there are more organizations than before which see the benefit of corporate membership (ALCAS 2009).

One of the reasons for this is the realization that LCA methodology is fundamental to carbon footprinting, which is gathering pace as the new Federal Government tries to 
implement a number of reporting measures to help control Australia's high per capita greenhouse emissions. It is fair to say that the many consulting firms and government programs are popularizing LCA in this way, albeit only in terms of a single LCA indicator. Another reason is the current Australian Life Cycle Inventory Database Initiative (AusLCI 2008). This aims to replace the relatively sparse and methodologically uneven data available on local production systems and represents the first major update since the original national database project began over 10 years ago. This activity is currently progressing on the basis of some government and industrial seed funding and the voluntary contributions of ALCAS members. To accelerate the work, we would welcome the participation of more of our international colleagues. Hopefully, these data will eventually be easily accessible by international researchers so they do not have to make environmentally pessimistic assumptions about the production of Australian exports.

\section{Conclusions and outlook}

The Australian LCA industry has benefited from connections with the international collaborators, including a number of research activities and participation in various SETAC committees, and ALCAS aims to foster relationships like these. Perhaps you have contacts in the head office of a multinational company with investments in Australia and can find your way to join us (in the abundant sunshine) for some LCA work on one of the many industries supplying raw materials and manufactures to overseas markets? Perhaps you work in an industry that is underrepresented in the data shown in this article. ALCAS will be happy to help connect you with the most relevant researchers here. While the nation's LCA publication rate, as a proportion of global contributions to four leading general LCA journals, has fallen over the last few years, 2009 is looking like a good year. Reasons for optimism include the current surge of interest in climate change, the slow but steady progress of the
AusLCI project, and the need to continue to be active in areas of LCA development such as water and biodiversity in which the country presents some unique environmental situations. These warrant further collaboration between local and international researchers.

Acknowledgement The author wishes to thank Matthias Schulz for the assistance with the classification of articles.

\section{References}

ALCAS (2009) Corporate members. Available at http://www.alcas. asn.au/about-us/corporate-members. Accessed on April 2009

AusLCI (2008) The Australian Life Cycle Inventory Database Initiative. Available at http://www.auslci.com.au/. Accessed on April 2009

Grant T, James KL, Lundie S (2001) ALCAS: Australian LCA Society New LCA Group to promote life cycle assessment in Australia. Int J Life Cycle Assess 6(6):323-324

Greene D (1992) Life cycle analysis. A view of the environmental impact of consumer products using clothes washing machines as an example. Melbourne, Deni Greene Consulting for the Australian Consumers' Association

Hes D (2001 July) Australian LCA projects. Available at http:// auslcanet.rmit.edu.au/Table.html. Accessed on April 2009

Lundie S, Peters G, Beavis P (2005) Quantitative systems analysis as a strategic planning approach for metropolitan water service providers. Water Sci Technol 52(9):11-20

OECD (2008) Education at a glance 2008. Paris, Organisation for Economic Co-operations and Development. ISBN 978-92-6404628-3

Schulz M, Peters G, Rowley H (2009) Tool for rapid cost and environmental assessment of water servicing strategies. Proceedings of the Sixth Australian Conference on Life Cycle Assessment, Melbourne, Australian Life Cycle Assessment Society

Smith A (2002) CRC for waste management and pollution control (1991-2003). Available at http://www.austehc.unimelb.edu.au/ asaw/biogs/A001941b.htm. Accessed on April 2009

UN (1993) System of national accounts 1993. Available at http:// unstats.un.org/unsd/sna1993/introduction.asp. Accessed on April 2009

UNSW (2008) An environmental rating scheme for air conditioning and refrigeration systems using LCA methodology. Available at http://www.cwwt.unsw.edu.au/lca/abstracts.html. Accessed on April 2009

Verghese K (2008) PIQET — Packaging Impact Quick Evaluation Tool. Available at http://www.cfd.rmit.edu.au/. Accessed on April 2009 